\title{
Auxiliary Theory and Multitrait-Multimethod Validation: A Review of Two Approaches
}

\author{
William R. Avison \\ The University of Western Ontario
}

\begin{abstract}
Althauser and Heberlein (1970) and Costner and Schoenberg (1973) have developed path analytic techniques for assessing the validity of indicators in multitrait-multimethod matrices. Both procedures involve the application of Costner's (1969) auxiliary theory. These approaches represent improvements on Campbell and Fiske's early procedures for testing for validity. This article examines these tech-
\end{abstract}

niques and demonstrates their applications. It is argued that the diagnosis of indicator ills by means of confirmatory factor analysis is especially useful: This technique not only tests the adequacy of a measurement model, but also estimates the parameters of the specified model. An empirical example of these techniques is presented.

Concern with the validity of measures has long been a central concern of psychologists and sociologists (Curtis \& Jackson, 1962; Bohrnstedt, 1970; Althauser \& Rubin, 1971). Of special interest is the evaluation of validity when indicators exist as measures of the same underlying concept or trait. In such instances, assessments of convergent and discriminant validity have been of major importance.

Campbell and Fiske (1959) proposed the use of a multitrait-multimethod (MTMM) correlation matrix as a means to assess systematically the discriminant and convergent validity of a set of measures. In a recent article in this journal, Schmitt (1978) noted several problems with the CampbellFiske method. He argued that a more powerful, objective technique for assessing validity is the application of confirmatory factor analysis to such correlation matrices. Since the MTMM matrix is analyzable by the set of factor analytic models described by Werts and Linn (1970), maximum likelihood estimates of the parameters in such models may be generated using techniques described by Jöreskog $(1969,1970)$.

In addition to Campbell and Fiske's technique and Schmitt's application of confirmatory factor analysis, Althauser and Heberlein (1970) and Costner and Schoenberg (1973) have proposed methods based on Costner's (1969) auxiliary theory approach that assess the validity of indicators. Althauser and Heberlein's procedure represents a self-contained validation technique, while Costner and Schoenberg's demonstrates how Costner's approach may be used in conjunction with confirmatory factor analysis to diagnose indicator ills. The objectives of the present paper are to describe these techniques and to compare them with the confirmatory factor analysis method described by Schmitt. 


\section{Costner's Auxiliary Theory Approach}

Costner (1969) has argued for the provision of statements that describe the connection between constructs and their empirical indicators. The development of these "rules of correspondence" is referred to as an auxiliary theory. If these relational statements are treated as any other propositions in a theoretical formulation, then their construction will allow for the estimation of epistemic correlations.

Assuming a measurement model similar to Figure 1, differential constant error (also known as differential bias, systematic measurement error, or correlated measurement error) may occur when errors in the measurement of a construct or indicator are associated with measurement errors of another concept or indicator. According to Costner, differential bias, unlike random error, does not necessarily result in an underestimation of the relationship between the abstract variables.

\section{Figure 1}

A Measurement Model That Satisfies the Consistency Criterion

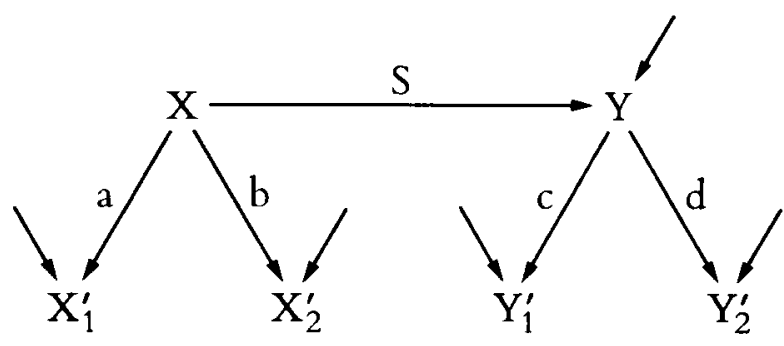

Using the auxiliary theory, three aspects of this measurement model can be ascertained. An estimate of each unknown coefficient can be derived. Differential bias (if any) can be identified; this would suggest either that certain indicators may be inadequate or that a new model must be specified. Third, the implications of the connections among variables on an abstract level can be tested. These three items of information can only be acquired if the model is just- or over-identified.

In Figure 1, six correlations will be generated from the data correponding to the model. This model provides the simplest demonstration of the use of consistency criterion equations for the identification of differential bias.

For this model, six equations can be derived:

$$
\begin{aligned}
& r_{X_{1}^{\prime} X_{2}^{\prime}}=a b \\
& r_{Y_{1}^{\prime} Y_{2}^{\prime}}=c d
\end{aligned}
$$




$$
\begin{aligned}
& r_{X_{1}^{\prime} Y_{1}^{\prime}}=a S c \\
& r_{X_{1}^{\prime} Y_{2}^{\prime}}=a S d \\
& r_{X_{2}^{\prime} Y_{1}^{\prime}}=b S c \\
& r_{X_{2}^{\prime} Y_{2}^{\prime}}=b S d
\end{aligned}
$$

Assuming non-zero correlations, we find that:

$$
\begin{aligned}
& \left(x_{X_{1}^{\prime} Y_{1}^{\prime}}\right)\left(r_{X_{2}^{\prime} Y_{2}^{\prime}}\right)=\left(r_{X_{1}^{\prime} Y_{2}^{\prime}}\right)\left(r_{X_{2}^{\prime} Y_{1}^{\prime}}\right) \\
& (a S c)(b S d)=(a S d)(b S c) \\
& a b s^{2} c d=a b S^{2} c d
\end{aligned}
$$

Equation 7 is the consistency criterion equation. When equality exists, this fulfills a necessary, but not sufficient, condition for the assumed absence of differential bias.

If, however, there is an error term, $w$, that affects both $X_{1}^{\prime}$ and $Y_{1}^{\prime}$ (as might be the case with a methods factor), then the model will take the form of Figure 2 . This specification alters only Equation 3 such that:

$$
\mathrm{r}_{\mathrm{X}_{2}^{\prime} \mathrm{Y}_{1}^{\prime}}=\mathrm{bSc}+\mathrm{ef}
$$

In this case, an inequality condition exists for the consistency criterion expressed in Equation 7. Under these circumstances, the presence of differential bias is confirmed. 
Figure 2

A Measurement Model

With a Specified Error Term

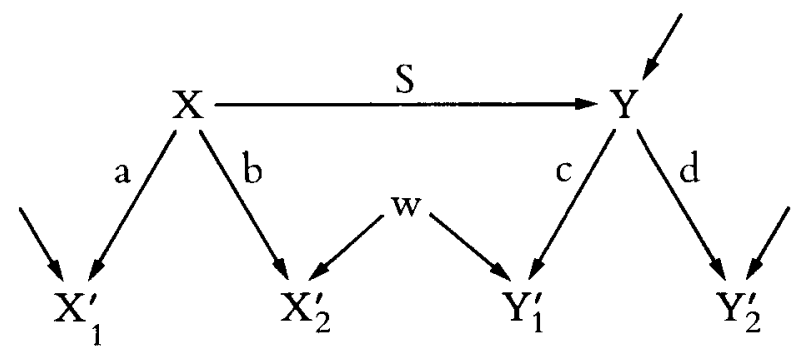

If the consistency criterion holds for Figure 1, unique estimates of each of the five path coefficients in the model can be calculated. For each path, two estimates will be derived; each pair will be equivalent if the consistency criterion holds. For example:

$$
\begin{aligned}
& s^{2}=\frac{\left(r_{X_{1}^{\prime} Y_{2}^{\prime}}\right)\left(r_{\left.X_{2}^{\prime} Y_{1}^{\prime}\right)}\right.}{\left(r_{X_{1}^{\prime} X_{2}^{\prime}}\right)\left(r_{\left.Y_{1}^{\prime} Y_{2}^{\prime}\right)}\right)}=\frac{\left(r_{X_{1}^{\prime} Y_{1}^{\prime}}\right)\left(r_{\left.X_{2}^{\prime} Y_{2}^{\prime}\right)}\right.}{\left(r_{X_{1}^{\prime} X_{2}^{\prime}}\right)\left(r_{\left.Y_{1}^{\prime} Y_{2}^{\prime}\right)}\right.} \\
& a^{2}=\left(r_{X_{1}^{\prime} X_{2}^{\prime}}\right) \frac{\left(r_{X_{1}^{\prime} Y_{2}^{\prime}}\right)}{\left(r_{X_{2}^{\prime} Y_{2}^{\prime}}\right)}=\left(r_{X_{1}^{\prime} X_{2}^{\prime}}\right) \frac{\left(r_{X_{1}^{\prime} Y_{1}^{\prime}}\right)}{\left(r_{X_{2}^{\prime} Y_{1}^{\prime}}\right)}
\end{aligned}
$$

Similar calculations provide solutions for the other epistemic paths and for the relationship between the two constructs. The procedures for doing so have been described by Hauser and Goldberger (1971).

Costner's approach to validation is somewhat different from that of Campbell and Fiske. Costner's analysis is not limited to multitrait-multimethod problems; rather, it is applicable to any multiple indicator measurement model. Figure 1 can be construed to represent a multitrait-multimethod model with two traits $(X$ and $Y)$ and two methods (subscripts on the indicators). Thus, the correlation between $X_{1}^{\prime}$ and $X_{2}^{\prime}$ represents a monotrait-heteromethod (MTHM) association, while the relationship between $X_{2}^{\prime}$ and $Y_{2}^{\prime}$ is a heterotrait-monomethod (HTMM) correlation. The association between $X_{1}^{\prime}$ and $Y_{2}^{\prime}$ is a heterotrait-heteromethod (HTHM) correlation.

According to Campbell and Fiske, evidence of discriminant validity exists if MTHM correlations are greater than HTMM or HTHM correlations. Algebraically, this may be expressed as

$$
r_{X_{i}^{\prime} Y_{j}^{\prime}}<r_{X_{i}^{\prime} X_{j}^{\prime}}>r_{X_{i}^{\prime} Y_{i}^{\prime}}
$$

(HTHM) (MTHM) (HTMM) 
where $X$ and $Y$ are traits and $i$ and $j$ are methods. With this as a given, there is no reason why HTMM correlations could not be zero. On the other hand, Costner has explicitly stated that such correlations must be non-zero if the consistency criterion is to hold. Indeed, if this were not the case, differential bias could not be identified using the Costner method.

\section{Althauser and Heberlein's Application}

Althauser and Heberlein have assessed the tenability of the Campbell-Fiske criteria for evaluating convergent and discriminant validity by restating these principles in path analytic terms. Figure 3 represents a path model where $X$ and $Y$ are traits; $F$ s are methods factors; and $X_{1}^{\prime}, X_{2}^{\prime}, Y_{1}^{\prime}, Y_{2}^{\prime}$ are indicators whose subscripts indicate which method was used. Path coefficients are indicated by $a, b$, $c$, and so forth; $S$ is the substantive relationship between $X$ and $Y$; and $q$ is the correlation between the methods factors. This model represents a reduced multitrait-multimethod matrix.

Figure 3

\section{A Reduced MTMM Measurement Model With Two Correlated Methods Factors}

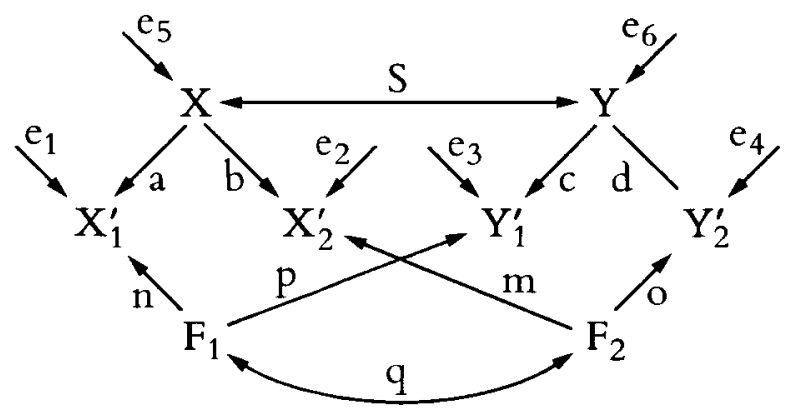

For this model, an example of a MTHM correlation expressed in path analytic terms is

$$
\mathrm{r}_{\mathrm{X}_{1}^{\prime} \mathrm{x}_{2}^{\prime}}=\mathrm{ab}+\mathrm{nqm}
$$

An HTHM correlation takes the form,

$$
\mathrm{r}_{\mathrm{X}_{1}^{\prime} \mathrm{Y}_{2}^{\prime}}=\mathrm{aSd}+\mathrm{nqo}
$$

An HTMM correlation can be expressed as

$$
r_{X_{1}^{\prime} Y_{1}^{\prime}}=a S c+n p
$$


According to Campbell and Fiske, convergent validity obtains when MTHM correlations are strong. In terms of Equation 14, this assumes that all six epistemic paths are relatively large and that the methods are independent $(q=0)$. While the first assumption is reasonable, the second is difficult to accept a priori. If the latter assumption cannot be made with assurance, it is possible that strong MTHM correlations may be due to correlated methods factors (the $n q m$ component).

There are three comparisons to make for assessing discriminant validity. First, MTHM correlations should exceed HTHM correlations:

$$
r_{X_{1}^{\prime} X_{2}^{\prime}}-r_{X_{1}^{\prime} Y_{2}^{\prime}}=(a b-a S d)+n q(m-o)
$$

This difference can be decomposed into two parts. The first is a function of the epistemic path coefficients and the substantive relationship. The second is due solely to methods paths and correlations. Any correlational difference that exists should therefore be due to this first component. Thus, $S$ must be fairly small. This is a reasonable condition to expect, for a large $S$ would question the existence of separate and distinguishable traits. Two conditions can result in a negligible value for the second component: Methods effects could be small or they could be of any magnitude but equal. This indeterminacy casts doubt on the efticacy of the first criterion for assessing discriminant validity.

The second desideratum requires that MTHM correlations be greater than HTMM correlations. This is represented by

$$
\mathrm{r}_{X_{1}^{\prime} X_{2}^{\prime}}-\mathrm{r}_{\mathrm{X}_{1}^{\prime} \mathrm{Y}_{1}^{\prime}}=(\mathrm{ab}-\mathrm{aSc})+\mathrm{n}(\mathrm{qm}-\mathrm{p})
$$

Assuming that $b=c$, the first component will represent a term roughly equivalent to $(1-S)$. Assuming positive epistemic path coefficients, this component will be positive in sign. The second term will be a function of the methods paths and the intercorrelation of methods. Assuming that all methods coefficients are of the same sign, this component will typically be a negative quantity. Thus, the magnitude of the correlational difference is dependent on the negative second component. Althauser and Heberlein have argued that the interpretation of large HTMM correlations as symptomatic of the presence of methods factors is dangerous where underidentified models are concerned; nevertheless, they found this particular criterion of Campbell and Fiske to be basically sound.

Campbell and Fiske's last criterion used to assess discriminant validity involves comparing correlations of corresponding position in the monomethod and heteromethod blocks. To demonstrate this, a third construct, $Z$, must be added; and it must be assumed that all path coefficients from $Z$ can be expressed as primes (') of the coefficients for $Y$. Thus,

$$
r_{X_{1}^{\prime} Y_{1}^{\prime}}-r_{X_{1}^{\prime} Z_{1}^{\prime}}=r_{X_{1}^{\prime} Y_{2}^{\prime}}-r_{X_{1}^{\prime} Z_{2}^{\prime}}
$$

Substituting Equations 15 and 16,

$$
(a S c+n p)-\left(a S^{\prime} c^{\prime}+n p^{\prime}\right)=(a S d+n q o)-\left(a S^{\prime} d^{\prime}+n q o^{\prime}\right)
$$


Thus,

$$
a\left(S d-S^{\prime} d^{\prime}\right)+n\left(p-p^{\prime}\right)=a\left(S d-S^{\prime} d^{\prime}\right)+n q\left(o-o^{\prime}\right)
$$

As before, the lefthand term on each side of the equation is a function of the epistemic paths, while those on the right of each side are dependent upon values of the methods path coefficients. According to Althauser and Heberlein, the problem that afflicted the first Campbell-Fiske criterion arises again. They, therefore, have concluded that the comparison of correlations in a multitraitmultimethod matrix does not provide a sufficiently rigorous assessment of convergent and discriminant validity; they argued that the Campbell-Fiske criteria for validation are tenuous to the extent that they must be underwritten by various assumptions, many of which require methodological bravado.

In response to the deficiencies of the Campbell-Fiske criteria, Althauser and Heberlein have presented an alternative approach to validation that involves an application of Costner's consistency criterion. Their procedure entails comparing one model (such as in Figure 1) with a specified alternative (such as in Figure 3). Assuming uncorrelated methods factors $(q=0)$ and substituting path coefficients into the consistency criterion (Equation 7),

$$
(a S c+n p)(b S d+m o)=(a S d)(b S c)
$$

Simplifying,

$$
a b S^{2} c d+n p b S d+m o a S c+n p m o=a b S^{2} c d
$$

It is apparent that the consistency criterion will be met only where $n p b S d+$ moaSc $+n p m o=0$. That is, if alternative models that specify methods factors are proposed (such as in Figure 3), $m, n, o$, and $p$ will be greater than zero, hence the inequality in the consistency equation. If the consistency criterion holds, then Althauser and Heberlein argue that alternative models can be rejected.

If the tetrad difference in the consistency criterion is not zero, Althauser and Heberlein suggest that the standard error of this difference should be computed by

$$
\sigma_{\text {dif }}=2 r(1-r) / \sqrt{N}
$$

where $r$ is the average of the four correlations in the tetrad difference and $N$ is the sample size. A cautionary note is warranted: This test is powerful only where $r$ exceeds .30 .

\section{Costner and Schoenberg's Method for Diagnosing Indicator Ills}

Costner and Schoenberg (1973) have made use of both Jöreskog's confirmatory factor analysis technique (Jöreskog, 1969; Jöreskog, 1970; Jöreskog, Gruvaeus, \& van Thillo, 1970; Jöreskog \& van Thillo, 1972; Jöreskog \& Sorbom, 1976) and Costner's consistency criterion approach to identify sources of invalidity in path models. While confirmatory factor analysis may indicate that "indicator flaws" exist within a given model, Costner and Schoenberg have argued that this technique provides 
few clues for pinpointing the exact nature of these difficulties. Their solution to this is the application of Costner's consistency criterion to submodels within the overall structural equation model.

Costner and Schoenberg have assumed an extremely simple measurement model (e.g., uncorrelated disturbance terms, no methods factors) and then used confirmatory factor analysis to estimate the parameters. They tested the adequacy of their model by comparing the observed correlation matrix to that which would be expected, given the parameters generated from the model's structure. If the hypothesized model is inaccurate, Costner and Schoenberg apply Costner's technique to examine the sources of poor fit within submodels.

Costner and Schoenberg (1973, p. 172) argued that

a large discrepancy between the observed and implied correlations for any given pair of variables . . . suggests that between those two variables there are sources of covariation that have been omitted from the initial model. This, in turn, suggests an examination of the residuals matrix to locate the largest discrepancies, a redesign of the model to provide for additional paths, and an estimate and "goodness of fit" test for the redesigned model. But this approach can be very misleading. The clues provided by the residuals matrix are highly fallible under certain circumstances.

Costner and Schoenberg have demonstrated that the specification of a correlated disturbance term between two indicators may reduce the residual correlation so that it becomes insignificant. They warned, however, that such a specification may result in a reconstructed model that does not resemble the one hypothesized. Thus, they have expressed concern for the development of measurement models that are in accord with the researcher's theoretical notions.

The Costner-Schoenberg technique involves taking all possible submodels of the form illustrated in Figure 2 and computing estimates of the substantive path between unmeasured traits from the indicator correlations. Thus, for a model such as in Figure 4, 27 such two-indicator submodels may be derived. For each submodel, two estimates of the substantive path coefficient can be calculated from Equation 7. These two estimates will be identical unless some unspecified correlated disturbance or methods factor exists between indicators of different traits.
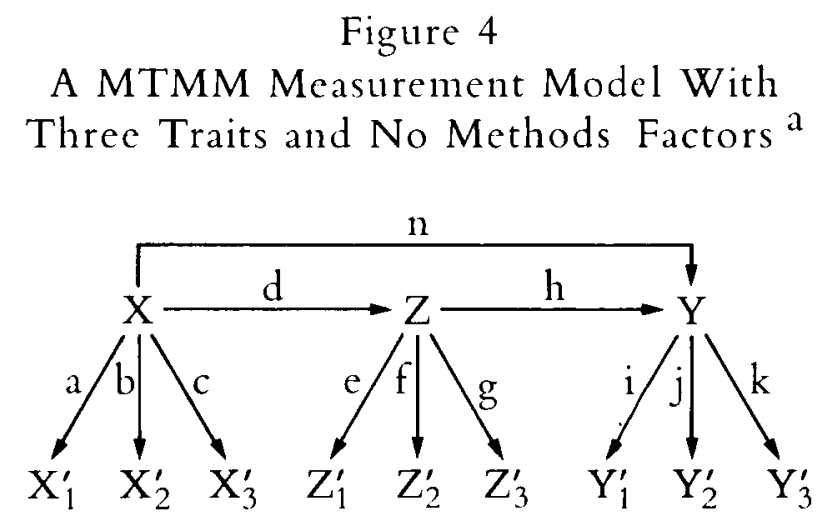

a For this and subsequent models,
disturbance terms have been deleted to
simplify the presentation of the models. 
Using this procedure, indicators that exhibit the most serious flaws can be identified. Thus, the nature of the measurement error in the structural equation model can be specified. Correlated errors between indicators of different traits measured by the same method are indicative of some type of methods factor. Correlated errors of indicators of different traits measured by different methods may signal the existence of a confounding effect of a trait on an indicator of another construct. Such a correlation may also suggest that the indicator is actually measuring a different trait "embedded" in the model.

\section{An Empirical Example}

The MTMM matrix presented in Table 1 is derived from data collected from 148 subjects (white, male Americans) who were part of the sample in Almond and Verba's Five Nation Civil Culture Study (1963). The three traits were the subjects' sense of participation in decision-making in the home (as a child), in the school (as a student), and on the job (as an employee). Each trait was measured by three methods: perceived freedom to participate, perceived impact of participation, and actual frequency of participation. While the data differed somewhat from more standard examples of MTMM situations, the three traits (participation as a child, as a student, and as an employee) have each been measured by three different questions (treated as measures).

An examination of MTHM (validity) diagonals indicated that the correlations were not high enough to conclude that there was convergent validity. Regarding discriminant validity, the data satisfied the minimal criteria suggested by Campbell and Fiske. Validity (MTHM) values were greater than HMHT correlations. Second, MTHM correlations were greater than corresponding HTMM ones. Third, there were distinguishable patterns of trait interrelationships in most of the heterotrait triangles for both mono- and hetero-method blocks. Thus, it could be concluded that there was suffi-

Table 1

Multitrait-Multimethod Correlations ${ }^{\text {a }}$

\begin{tabular}{crrrrrrrrr}
\hline $\begin{array}{c}\text { Trait-Method } \\
\text { Unit }\end{array}$ & $\mathrm{X}_{1}$ & $\mathrm{Y}_{1}$ & $\mathrm{Z}_{1}$ & $\mathrm{X}_{2}$ & $\mathrm{Y}_{2}$ & $\mathrm{z}_{2}$ & $\mathrm{X}_{3}$ & $\mathrm{Y}_{3}$ & $\mathrm{Z}_{3}$ \\
\hline $\mathrm{X}_{1}$ & & & & & & & & \\
$\mathrm{Y}_{1}$ & 0.00 & & & & & & & \\
$\mathrm{Z}_{1}$ & 0.26 & 0.00 & & & & & & \\
$\mathrm{X}_{2}$ & 0.50 & 0.14 & 0.10 & & & & & \\
$\mathrm{Y}_{2}$ & -0.08 & 0.59 & -0.05 & 0.10 & & & & \\
$\mathrm{z}_{2}$ & 0.26 & 0.02 & 0.45 & 0.25 & -0.03 & & & \\
$\mathrm{X}_{3}$ & 0.35 & -0.02 & 0.08 & 0.26 & 0.04 & 0.13 & & \\
$\mathrm{Y}_{3}$ & 0.11 & 0.28 & 0.00 & 0.16 & 0.22 & 0.02 & 0.20 & \\
$\mathrm{Z}_{3}$ & 0.23 & -0.07 & 0.60 & 0.36 & -0.08 & 0.43 & 0.07 & 0.09 \\
\hline
\end{tabular}

$\mathrm{a}_{\mathrm{X}}, \mathrm{Y}$, and $\mathrm{Z}$ refer to traits; 1,2 , and 3 refer to methods. 
cient (although weak) evidence to infer discriminant validity. Nevertheless, the data left some doubt about the strength of these inferences.

\section{Application of Costner's Approach}

Using Costner's approach, the model implied by the MTMM matrix is first specified. That model is portrayed in Figure 4. It consists of three traits and three indicators per trait. No differential bias is hypothesized. For this model, 27 separate consistency checks may be computed using the criterion expressed in Equation 7. These consistency checks may be classified into three groups of nine, corresponding to those for the correlations among $X$ and $Y, Y$ and $Z$, and $X$ and $Z$, respectively.

It should be recalled that Costner has also specified an algebraically similar test for consistency that entails the derivation of substantive paths between the unmeasured traits. For the model in Figure 4, this involves the computation of estimates of paths $d, h$, and $n$, using the generalized form of Equation 11. It should be noted that Equation 11 provides the formula for computing the square of the path; therefore, the square root of the equation must be taken to calculate the path itself.

With three indicators per construct, nine pairs of estimates of each substantive path $(d, h$, and $n$. respectively) may be derived. Thus, there will be a total of 54 estimates generated. These estimates, which are indicative of measurement error, are presented in Table 2 . An examination of these data reveals substantial differences among the estimates of each path. In addition, some paths could not be computed (the squares of the paths being negative in sign). Although we have been made aware that there must be indicator flaws (and, therefore, some invalidity), this procedure provided little information about its specific location. That is, an inspection of Table 2 gives no indication of which indicators may be invalid. Rather, this method allows only for a test of the adequacy of the model. Obviously, the hypothesized model in Figure 4 cannot be accurate, given the variation in path estimates and the inequalities in the consistency criteria. It was, therefore, necessary to specify an alternative hypothetical model.

At this point, Costner and Schoenberg's method becomes useful. For purposes of clarity and simplicity, construct $Z$ and its indicators have been deleted. In so doing, the number of possible twoindicator submodels was reduced to nine, thus making the example more manageable.

The first step in diagnosing indicator ills involves testing the model specified in Figure 4 (remembering that construct $Z$ and its indicators have now been deleted). By specifying the structure of the model and inputting the correlation matrix into a confirmatory factor analysis program, such a test is accomplished. Several similar software packages (Jöreskog \& Sorbom, 1976; Jöreskog \& van Thillo, 1972; Jöreskog et al., 1970) are available for such analyses. The present analysis made use of ACOVS (Jöreskog et al., 1970). Using this technique, path coefficients are estimated from the correlation matrix, given the particular hypothesized structure of the model. Then, a matrix of expected correlations is derived from the path estimates. The differences between the observed and expected correlation matrices results in a residual correlation matrix. A chi-square goodness of fit test can then be computed to test whether there is a significant difference between the expected and observed matrices.

Table 3 displays the residual correlation matrix corresponding to Figure 4 (with $Z$ deleted). The chi-square (17.3212) is significant, indicating that the data does not fit the hypothesized model. This inference is in accord with the conclusions previously made after subjecting the data to Costner's consistency criteria in the manner of Althauser and Heberlein.

Given the lack of fit, Costner and Schoenberg have asserted that all nine possible submodels that take the form of Figure 1 should be examined so that the locus of error can be isolated. This entails 
Table 2

Consistency Checks Using Estimates of Substantive Paths

\begin{tabular}{|c|c|c|c|}
\hline \multirow[b]{2}{*}{ Indicators Used ${ }^{b}$} & \multicolumn{3}{|c|}{ Substantive Paths ${ }^{a}$} \\
\hline & $\mathrm{d}$ & $\mathrm{h}$ & $\mathrm{n}$ \\
\hline $\mathrm{X}_{1}^{\prime} \mathrm{X}_{2}^{\prime} \mathrm{Y}_{1}^{\prime} \mathrm{Y}_{2}^{\prime}$ & $\begin{array}{l}0.54 \\
0.35\end{array}$ & $\begin{array}{l}0.00 \\
0.00\end{array}$ & $\begin{array}{c}0.00 \\
(-0.04)\end{array}$ \\
\hline$X_{1}^{\prime} X_{2}^{\prime} Y_{1}^{\prime} Y_{3}^{\prime}$ & $\begin{array}{l}0.66 \\
0.28\end{array}$ & $\begin{array}{l}0.00 \\
0.00\end{array}$ & $\begin{array}{l}0.00 \\
0.33\end{array}$ \\
\hline $\mathrm{X}_{1}^{\prime} \mathrm{X}_{2}^{\prime} \mathrm{Y}_{2}^{\prime} \mathrm{Y}_{3}^{\prime}$ & $\begin{array}{l}0.66 \\
0.52\end{array}$ & $\begin{array}{c}(-0.02) \\
0.00\end{array}$ & $\begin{array}{c}(-0.12) \\
0.32\end{array}$ \\
\hline $\mathrm{X}_{1}^{\prime} \mathrm{X}_{3}^{\prime} \mathrm{Y}_{1}^{\prime} \mathrm{Y}_{2}^{\prime}$ & $\begin{array}{l}0.54 \\
0.36\end{array}$ & $\begin{array}{l}0.00 \\
0.10\end{array}$ & $\begin{array}{l}0.00 \\
0.10\end{array}$ \\
\hline$X_{1}^{\prime} X_{3}^{\prime} Y_{1}^{\prime} Y_{3}^{\prime}$ & $\begin{array}{l}0.30 \\
0.30\end{array}$ & $\begin{array}{l}0.00 \\
0.00\end{array}$ & $\begin{array}{c}0.00 \\
(-0.03)\end{array}$ \\
\hline$X_{1}^{\prime} X_{3}^{\prime} Y_{2}^{\prime} Y_{3}^{\prime}$ & $\begin{array}{l}0.35 \\
0.45\end{array}$ & $\begin{array}{c}(-0.03) \\
0.00\end{array}$ & $\begin{array}{c}(-0.21) \\
0.24\end{array}$ \\
\hline$X_{2}^{\prime} X_{3}^{\prime} Y_{1}^{\prime} Y_{2}^{\prime}$ & $\begin{array}{l}0.33 \\
0.41\end{array}$ & $\begin{array}{l}0.00 \\
0.10\end{array}$ & $\begin{array}{c}0.20 \\
(-0.01)\end{array}$ \\
\hline$X_{2}^{\prime} X_{3}^{\prime} Y_{1}^{\prime} Y_{3}^{\prime}$ & $\begin{array}{l}0.20 \\
0.42\end{array}$ & $\begin{array}{c}0.14 \\
(-0.01)\end{array}$ & $\begin{array}{c}0.62 \\
(-0.04)\end{array}$ \\
\hline$X_{2}^{\prime} X_{3}^{\prime} Y_{2}^{\prime} Y_{3}^{\prime}$ & $\begin{array}{l}0.40 \\
0.65\end{array}$ & $\begin{array}{l}(-0.02) \\
(-0.02)\end{array}$ & $\begin{array}{l}0.59 \\
0.33\end{array}$ \\
\hline
\end{tabular}

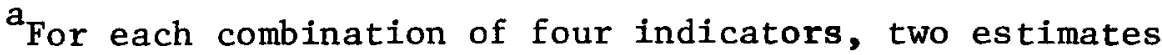
of the path coefficient are possible as in Equation [11].

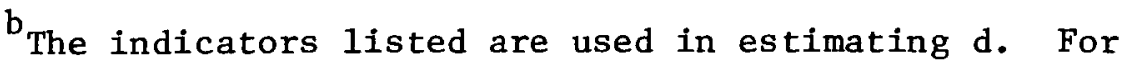
estimating $h$, the reader should substitute $Z$ 's for $X^{\prime} s$. To estimate $n, Z^{\prime} s$ should be substituted for $Y^{\prime} s$.

$c$ Values in parentheses are squares of path estimates whose roots could not be computed because of the negative sign. 
Table 3

Residual Correlation Matrix for Figure $4^{a}$

\begin{tabular}{rrrrrrr}
\hline & $\mathrm{X}_{1}^{\prime}$ & $\mathrm{X}_{2}^{\prime}$ & $\mathrm{X}_{3}^{\prime}$ & $\mathrm{Y}_{1}^{\prime}$ & $\mathrm{Y}_{2}^{\prime}$ & $\mathrm{Y}_{3}^{\prime}$ \\
\hline $\mathrm{X}_{1}^{\prime}$ & 0.009 & & & & & \\
$\mathrm{X}_{2}^{\prime}$ & 0.006 & 0.001 & & & & \\
$\mathrm{X}_{3}^{\prime}$ & 0.018 & -0.026 & 0.000 & & & \\
$\mathrm{Y}_{1}^{\prime}$ & -0.042 & 0.097 & -0.046 & 0.014 & & \\
$\mathrm{Y}_{2}^{\prime}$ & -0.120 & 0.058 & 0.011 & 0.006 & -0.001 & \\
$\mathrm{Y}_{3}^{\prime}$ & 0.091 & 0.139 & 0.192 & 0.010 & -0.021 & 0.000 \\
\hline
\end{tabular}

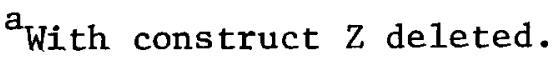

the computation of the discrepancies between the two estimates of the substantive path, $n$, for each of the nine submodels. This discrepancy is given by

$$
\left(r_{X_{i}^{\prime} Y_{j}^{\prime}}\right)\left(r_{X_{k}^{\prime} Y^{\prime}}\right)-\left(r_{X_{i}^{\prime} Y_{m}^{\prime}}\right)\left(r_{X_{k}^{\prime} Y_{j}^{\prime}}\right)
$$

These differences for each submodel are reported in Table 4. An examination of these discrepancies leads to the tentative hypothesis of the existence of a methods factor operating on $X_{2}^{\prime}$ and $Y_{2}^{\prime}$. It is observed that the two largest discrepancies $(.2270$ and .0252$)$ occur in submodels that have these two indicators present. Thus, the model to be tested would now take the form illustrated in Figure 5.

Table 4

Estimate Discrepancies for Two-Indicator Submodels ${ }^{a}$

\begin{tabular}{lc}
\hline Submode1 & Discrepancy \\
\hline$X_{1}^{\prime} X_{2}^{\prime} Y_{1}^{\prime} Y_{2}^{\prime}$ & 0.0010 \\
$X_{1}^{\prime} X_{2}^{\prime} Y_{1}^{\prime} Y_{3}^{\prime}$ & 0.0146 \\
$X_{1}^{\prime} X_{2}^{\prime} Y_{2}^{\prime} Y_{3}^{\prime}$ & 0.2270 \\
$X_{1}^{\prime} X_{3}^{\prime} Y_{1}^{\prime} Y_{2}^{\prime}$ & 0.0013 \\
$X_{1}^{\prime} X_{3}^{\prime} Y_{1}^{\prime} Y_{3}^{\prime}$ & 0.0031 \\
$X_{1}^{\prime} X_{3}^{\prime} Y_{2}^{\prime} Y_{3}^{\prime}$ & 0.0197 \\
$X_{2}^{\prime} X_{3}^{\prime} Y_{1}^{\prime} Y_{2}^{\prime}$ & 0.0068 \\
$X_{2}^{\prime} X_{3}^{\prime} Y_{1}^{\prime} Y_{3}^{\prime}$ & 0.0039 \\
$X_{2}^{\prime} X_{3}^{\prime} Y_{2}^{\prime} Y_{3}^{\prime}$ & 0.0252 \\
\hline
\end{tabular}

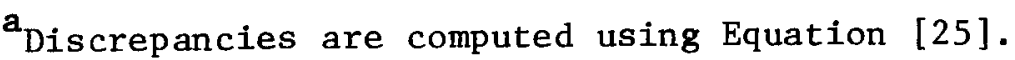


Figure 5

The MTMM Measurement Model

With One Methods Factor Specified

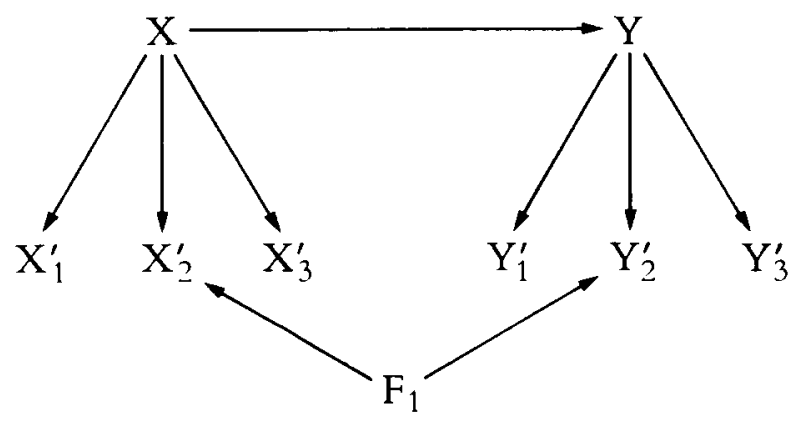

When this model is tested by confirmatory factor analysis, the residual correlations in Table 5 were reduced considerably. Indeed, the chi-square goodness of fit (11.69) is statistically insignificant. This indicates that there is an adequate fit of the data to the model. Substantively, this methods factor is interpretable if the referents of the traits and methods are recalled. Trait $X$ referred to sense of participation as a child; Trait $Z$ corresponded to sense of participation as an employee. The second method consisted of asking respondents to indicate whether or not they perceived their participation to have any impact. It is conceivable that respondents' present perceptions (as employees) may be inextricably related to their perceptions of their childhood experiences, thus contributing to systematic error in these indicators.

There may be other sources of systematic error that flaw the indicators, since relatively high residual correlations in Table 5 are observed between $Y_{3}^{\prime}$ and each of the indicators of construct $X$. No other residual correlation is sufficiently large to be problematic. Referring back to the discrepancies between estimates for the submodels in Table 4, it can be noted that no observable pattern exists that justifies the hypothesis of a correlated error term between $Y_{3}^{\prime}$ and any one indicator of construct $X$.

Table 5

Residual Correlation Matrix for Figure 5

\begin{tabular}{rrrrrrr}
\hline & $\mathrm{X}_{1}^{\prime}$ & $\mathrm{X}_{2}^{\prime}$ & $\mathrm{X}_{3}^{\prime}$ & $\mathrm{Y}_{1}^{\prime}$ & $\mathrm{Y}_{2}^{\prime}$ & $\mathrm{Y}_{3}^{\prime}$ \\
\hline $\mathrm{X}_{1}^{\prime}$ & 0.010 & & & & & \\
$\mathrm{X}_{2}^{\prime}$ & 0.006 & 0.005 & & & & \\
$\mathrm{X}_{3}^{\prime}$ & 0.025 & -0.019 & 0.002 & & & \\
$\mathrm{Y}_{1}^{\prime}{ }^{\prime \prime}$ & 0.003 & 0.003 & -0.020 & 0.028 & & \\
$\mathrm{Y}_{2}^{\prime}$ & -0.051 & 0.000 & 0.051 & 0.023 & 0.009 & \\
$\mathrm{Y}_{3}^{\prime}$ & 0.110 & 0.103 & 0.203 & 0.010 & -0.001 & 0.004 \\
\hline
\end{tabular}


Rather, it appears that all three indicators of $X$ are confounded with $Y_{3}^{\prime}$. Thus, it may be that there is a direct effect of construct $X$ on $Y_{3}^{\prime}$. Substantively, there is also reason to justify this hypothesized path. It seems possible that an individual's sense of participation in decision-making as a child may affect his/her behavior as an adult or as an employee; that is, there may be a direct relationship between childhood socialization experiences and current behavior as reported to an interviewer. Thus, there may be some nature of an inhibitory-disinhibitory effect operating. If childhood experiences have led an individual to perceive that participation in decision-making makes a difference, then he/she may be more likely to participate in decision-making on the job as an employee. In other words, indicator $Y_{3}^{\prime}$ is related more closely to childhood experiences than to present perceptions of the situation.

While this theoretical rationale is rather tentative, it is meant only to convey the notion that Costner and Schoenberg have stressed: The specification of new models must take into account both the data and whatever body of theory exists on the subject. Again, emphasis must be placed on the notion that Costner and Schoenberg's method attempts to integrate existing theory with this particular statistical technique. They have argued that a danger of ignoring theory is the development of models that do not resemble the model originally hypothesized.

Given the data and these theoretical notions, the second hypothesized model would take the form of Figure 6. The results of the confirmatory factor analysis of this model indicate that the specification of the path from $X$ to $Y_{3}^{\prime}$ greatly reduces the residual correlation (Table 6). The chisquare value (6.63) demonstrates that the observed and expected correlation matrices are not significantly different. An examination of the residual correlation matrix shows that the only remaining residual that is at all large is that between $X_{3}^{\prime}$ and $Y_{3}^{\prime}$. However, there is some doubt whether the specification of a methods factor would reduce this residual, since the discrepancies in estimates in Table 4 are not consistently large for all submodels that include both $X_{3}^{\prime}$ and $Y_{3}^{\prime}$. Indeed, further analysis reveals that the specification of a methods factor does not reduce the residual correlation to any appreciable extent. Thus, it can be concluded that the model hypothesized in Figure 6 has been tested and accepted as adequate.

Figure 6

The MTMM Measurement Model

With One Methods Factor and a

Confounding Path Specified

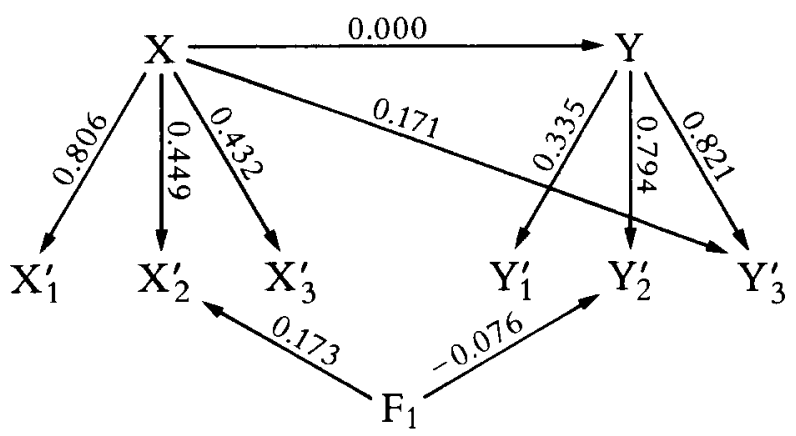

Downloaded from the Digital Conservancy at the University of Minnesota, http://purl.umn.edu/93227. 
Table 6

Residual Correlation Matrix for Figure 6

\begin{tabular}{rrrrrrr}
\hline & \multicolumn{1}{c}{$\mathrm{X}_{1}^{\prime}$} & $\mathrm{X}_{2}^{\prime}$ & $\mathrm{X}_{3}^{\prime}$ & $\mathrm{Y}_{1}^{\prime}$ & $\mathrm{Y}_{2}^{\prime}$ & $\mathrm{Y}_{3}^{\prime}$ \\
\hline $\mathrm{X}_{1}^{\prime}$ & 0.000 & & & & & \\
$\mathrm{X}_{2}^{\prime}$ & 0.002 & 0.000 & & & & \\
$\mathrm{X}_{3}^{\prime}$ & -0.002 & -0.006 & 0.000 & & & \\
$\mathrm{Y}_{1}^{\prime}$ & 0.004 & -0.004 & -0.019 & 0.000 & & \\
$\mathrm{Y}_{2}^{\prime}$ & -0.016 & 0.006 & 0.069 & 0.000 & 0.000 & \\
$\mathrm{Y}_{3}^{\prime}$ & -0.027 & -0.007 & 0.130 & 0.003 & -0.003 & 0.000 \\
\hline
\end{tabular}

Given that a model which is a reasonable fit of the data has been specified, its parameters can now be estimated. Again, this is accomplished by the maximum likelihood technique of confirmatory factor analysis. The estimated path coefficients for each parameter are entered in Figure 6 . These estimates suggest that $X_{1}^{\prime}$ may be the only valid indicator of construct $X$, while construct $Y$ may be validly measured by indicators $Y_{1}^{\prime}$ and $Y_{2}^{\prime}$. Furthermore, from observing the path linking $X$ with $Y_{3}^{\prime}$. there is some indication that this indicator is confounded with construct $X$ and may, therefore, be a poor measure.

\section{A Comparison with Schmitt's Application of Confirmatory Factor Analysis}

Schmitt's application of confirmatory factor analysis appears to focus primarily on testing the goodness of fit of alternative models. In so doing, emphasis is placed on finding the path analytic model that best reproduces the MTMM matrix. To the extent that models with trait and trait-method correlations fit the data, there is a lack of discriminant validity.

Althauser and Heberlein's use of Costner's consistency criterion provides a similar test for discriminant validity. They have argued that a hypothesized model which assumes uncorrelated methods can be compared with alternative models that imply methods correlations or trait-methods correlations. If Costner's consistency criterion holds, these alternative models can be rejected. It can then be concluded that the original model exhibits some satisfactory degree of discriminant validity.

While Althauser and Heberlein have accurately pointed to the flaws in the Campbell-Fiske method, their application of Costner's auxiliary theory has its own limitations. There is the possibility of conceptual and mathematical confusion in going beyond three constructs and three indicators per construct. The number of possible alternative models that would have to be tested increases rapidly as the model becomes more complex. Accordingly, the mapping of methods paths and interrelationships becomes more difficult. This method, then, seems to be restricted to relatively simple measurement models.

Further, this method appears to be less powerful as a test of discriminant validity than the method proposed by Schmitt. Although it seems that the Althauser-Heberlein approach and the application of confirmatory factor analysis may often lead to similar conclusions (as in the case of our empirical example), confirmatory factor analysis enables the researcher to take into account a greater number of alternative models (Mayer \& Younger, 1974). 
These limitations suggest that the Althauser and Heberlein approach may provide only a rough test of the validity of a specific measurement model. This, however, may be useful to many researchers, especially those who do not have access to confirmatory factor analysis programs. In such cases, the use of the Costner criterion provides the only means for estimating path coefficients in the measurement model.

A more useful application of Costner's technique has been demonstrated by Costner and Schoenberg. Their use of confirmatory factor analysis has objectives that appear to be somewhat different from Schmitt's. While Schmitt appears to be more interested in assessing discriminant validity, Costner and Schoenberg emphasize the specification of a model that fits the data and the estimation of path coefficients in the specified model. In specifying the model, Costner and Schoenberg seek the most parsimonious one, which also complements whatever theory and research is available:

Substantive knowledge of indicator characteristics may also provide valuable leads to correlated errors among indicators. There is no intent here to propose that such substantive leads be disregarded. Rather, our search has been for a general, codifiable procedure that may be used to supplement such substantive leads or provide independent support for their plausibility. (Costner \& Schoenberg, 1973, p. 199)

Costner and Schoenberg begin with the simplest measurement model and specify sources of systematic variation. Their approach involves the application of Costner's consistency criterion to identify these flaws in the original model. On the other hand, Schmitt appears to test various "nested" models by making successive chi-square comparisons. He has admitted that this procedure is a speculative and exploratory one. The procedures advocated by Costner and Schoenberg appear to provide a more systematic method for identifying measurement error.

Perhaps the most important contribution of Costner and Schoenberg relates to the improvement of causal analysis. The specification of measurement error in structural equation models provides a more accurate quantitative estimate of the relationship between unmeasured constructs and of the epistemic path coefficients between constructs and their indicators. Costner and Schoenberg's diagnostic approach protects the researcher from inferring some causal link between constructs that, on closer inspection, may be a function of systematic measurement error.

The procedures outlined by Schmitt and by Costner and Schoenberg should not be construed to be competitive. Schmitt has correctly noted the advantages of confirmatory factor analysis over the criteria proposed by Campbell and Fiske. Costner and Schoenberg have advocated a method that complements Schmitt's, making it possible for researchers to estimate specific paths with greater accuracy and to identify indicators that are flawed.

The statistical advantages of confirmatory factor analysis have been noted by Costner and Schoenberg and by Schmitt. Tests of goodness of fit enable the researcher to ascertain immediately whether measurement error affects the model. Additionally, a large number of models may be specified and tested with considerable ease. Last, the confirmatory factor analysis procedure subsumes both the Campbell-Fiske approach and the Althauser-Heberlein technique (Alwin, 1974, p. 102). Thus, one need not subject oneself to the tedious task of calculating consistency checks. These need only be computed if one wishes to diagnose the inadequate model in the interests of estimating path coefficients at some later point.

Thus, there are distinct advantages of the method suggested by Costner and Schoenberg. Their technique provides a procedure that complements the use of confirmatory factor analysis suggested by Schmitt. If researchers are concerned with specifying the nature and locus of measurement errors in multiple indicator measurement models, they may find this technique useful. 


\section{References}

Almond, G., \& Verba, S. The civic culture: political attitudes and democracy in five nations. Princeton: Princeton University Press, 1963.

Althauser, R. P., \& Heberlein, T. A. Validity and the multitrait-multimethod matrix. In E. F. Borgatta \& G. W. Bohrnstedt (Eds.), Sociological methodology, 1970. San Francisco: Jossey-Bass, 1970.

Althauser, R. P., \& Rubin, D. Measurement error and regression to the mean in matched samples. Social Forces, 1971, 50, 206-214.

Alwin, D. F. Approaches to interpretation of relationships in the multitrait-multimethod matrix. In $\mathrm{H}$. L. Costner (Ed.), Sociological Methodology, 1973-1974. San Francisco: Jossey-Bass, 1974.

Bohrnstedt, G. W. Reliability and validity assessment in attitude measurement. In G. F. Summers (Ed.), Attitude measurement. Chicago: Rand McNally, 1970.

Campbell, D. T., \& Fiske, D. W. Convergent and discriminant validation by the multitrait-multimethod matrix. Psychological Bulletin, 1959, 56 , 81-105.

Costner, H. L. Theory, deduction, and rules of correspondence. American Journal of Sociology, $1969,75,245-263$.

Costner, H. L., \& Schoenberg, R. Diagnosing indicator ills in multiple indicator models. In A. S. Goldberger \& O. D. Duncan (Eds.), Structural equation models in the social sciences. New York: Seminar Press, 1973.

Curtis, R. F., \& Jackson, E. F. Multiple indicators in survey research. American Journal of Sociology, 1962, 68, 195-204.

Hauser, R. M., \& Goldberger, A. S. The treatment of unobservable variables in path analysis. In H. L. Costner (Ed.), Sociological Methodology, 1971. San Francisco: Jossey-Bass, 1971.

Jöreskog, K. G. A general approach to confirmatory maximum-likelihood factor analysis. Psychometrika, 1969, 34, 183-202.
Jöreskog, K. G. A general method for analysis of covariance structures. Biometrika, 1970,57, 239-251.

Jöreskog, K. G., \& Sorbom, D. LISREL III: Estimation of linear structural equation systems by maximum likelihood methods. Chicago: National Educational Resources, Inc., 1976.

Jöreskog, K. G., \& van Thillo, M. LISREL: A general computer program for estimating a linear structural equation system involving multiple indicators of unmeasured variables. Princeton, NJ: Educational Testing Service Research Bulletin, 1972.

Jöreskog, K. G., Gruvaeus, G. T., \& van Thillo, M. ACOVS: A general computer program for analysis of covariance structures. Princeton, NJ: Educational Testing Service, 1970.

Mayer, L. S., \& Younger, M. S. Multiple indicators and the relationship between abstract variables. In D. R. Heise (Ed.), Sociological Methodology, 1975. San Francisco: Jossey-Bass, 1974.

Schmitt, N. Path Analysis of multitrait-multimethod matrices. Applied Psychological Measurement, 1978, 2, 157-173.

Werts, C. E., \& Linn, R. L. Path analysis: Psychological examples. Psychological Bulletin, 1970, 74, 193-212.

\section{Acknowledgements}

The author thanks Dr. Michael W. Gillespie of The University of Alberta for his comments on an earlier version of this paper.

\section{Author's Address}

William R. Avison, Department of Sociology, The University of Western Ontario, London, Ontario, Canada N6A 5C2 